\title{
Characterization of Carboxylated-SWCNT Based Potentiometric DNA Sensors by Electrochemical Technique and Comparison with Potentiometric Performance
}

\section{Mamun M A, A. J. Saleh Ahammad}

Department of Chemistry, Jagannath University, Dhaka, Bangladesh

\begin{abstract}
Aptasensors for detection of thrombin were produced by covalently linking aptamer (ssDNA) to cSWCNT. Those biosensors were fully characterized by cyclic voltammetry to evaluate the electrode surface charge/ligand density. We performed the CV studies of electrostatically bound $\left[\mathrm{Ru}\left(\mathrm{NH}_{3}\right)_{6}\right]^{3+}$ redox markers on aptamer surfaces and calculated aptamer surface charge density from the $\mathrm{CV}$ data. Potentiometric detection of thrombin allows then the correlation with the $\mathrm{CV}$ results. The electrode surfaces containing higher amount of aptamers exhibited better performance in potentiometric measurements. These investigations will introduce the pathway to build reusable and regenarable aptasensors including a simple, accurate and precise estimation of aptemer surface charge density to characterize the surface and hence to ensure the quality of apatsensors.
\end{abstract}

Keywords: Aptamers; cSWCNT; Cyclic voltammetry; Potentiometry; Electrical double layer; Redox capacitance; Surface coverage; Charge density

\section{Introduction}

The immediate detection of biological macro molecules, either pathogens or proteins, is one of the future challenges in medicine and diagnostics [1]. In this context, aptamers have shown their enormous potential in analytical bioassays as alternative to traditional antibodies [2]. This new recognition element (ssDNA or RNA) selected by in vitro processes against a target analyte, have been employed in unlimited kind of devices because of their excellent specificity to large variety of compounds, sensitivity, stability, high purity and reproducibility. Various strategies and technologies of aptamer based protein detections have been developed, such as colorimetric, fluorescence, chemiluminescence, Surface Plasmon Resonance (SPR) and electrochemical detection [3]. Among them, electrochemistry methods have attracted particular attention in the development of aptasensors because of their high sensitivity, inherent simplicity, miniaturization, low production cost and power requirements compared to others methods [4]. On the basis of instrumentation, several kinds of electrochemical aptasensors have been fabricated, including amperometric [3b], potentiometric and impedance transducers [3c]. In recent years, taking advantage of their high stability and labelling convenience, nanomaterials (carbon nanotubes, graphene, gold nanoparticles) were employed as signal amplification elements in various DNA or protein electrochemical assays [5]. This amplification of signal has made possible aptasensor to detect ultra low concentration of analytes [6]. For example, potentiometric aptasensors were reported for fast detection of very low amounts of pathogens or proteins [7]. Those aptasensors can successfully detect single bacteria in $5 \mathrm{~mL}$ in few seconds. The potentiometric aptasensors is produced by covalently linking the aptamer (previously modified by an amine moiety) to the carboxylic groups of the SWCNT ends and defects. For instance, the thrombin aptasensor are able to detect the target protein in few seconds with high sensitivity comparable to the thrombin physiological concentrations [7b]. The structure-dependent conductive properties of Carbon Nanotubes (CNT) promote electron-transfer reactions at low potentials. This characteristic, along with their high surface to volume ratio, provides the ground for unique biochemical sensing systems. In order to fully optimize the performance parameters of aptasensors, the characterization of the surface (e.g. the density of aptamers and the particular conformation of the aptamers) is of major importance. Techniques such as Atomic Force Microscopy (AFM), Transmission Electron Microscopy (TEM), scanning electron microscopy (SEM), Scanning Tunneling Microscopy (STM), or fluorescence spectroscopy still show limitations to afford quantitative characterization of these aptasensors surface. Noteworthy, more convenient approaches involving electrochemical or spectroscopic techniques have been presented. For instance, quantification of hybridized and dehybridized 70-100 $\mathrm{fmol} / \mathrm{mm}^{2}$ of thiol-tethered DNA on Au substrate were reported by Peterlinz et al. using two-color surface plasmon resonance spectroscopy [8]. In the same way, SPR, FTIR (Fourier transform infrared) and XPS (X-Ray photoelectron spectroscopy) have been reported [8]. Dmitri et al. [8c] have described the complementary use of XPS and FTIR spectroscopy to observe that buffers with divalent salts dramatically increase the efficiency of immobilization of DNA. Nevertheless, almost all of these methods or techniques are demanding but not cost effective. As an alternative, Yu et al. [9] quantified ssDNA and dsDNA on modified gold electrode using a simple procedure based on the Cyclic Voltammetric (CV) response of ruthenium complex redox markers, which are electrostatically bound to the phosphodiester groups of DNA [9]. In 2005, Lao et al. [10] noted that CV gave less than $25 \%$ of the value obtained by ChronoCoulometry (CC) in their studies [10]. Furthermore, both CV and CC were used in determination of DNA surface density on gold electrodes [11]. Such approach was allowed to develop advanced procedure for the preparation of DNA modified gold chips with a relatively high surface coverage $(2.2 \pm$ $0.3 \times 10^{13}$ molecules $\mathrm{cm}^{-2}$ ). However, in spite of the tremendous potential held by SWCNT based aptasensors, very little attention has been

${ }^{*}$ Corresponding author: Mamun M A and Saleh Ahammad AJ, Department of Chemistry, Jagannath University, Dhaka, Bangladesh, Tel: 8802958 3794; Fax: 8802 7113713; E-mail: zithrox@gmail.com and ajsahammad@chem.jnu.ac.bd

Received May 27, 2014; Accepted July 04, 2014; Published July 10, 2014

Citation: Mamun MA, Saleh Ahammad AJ (2014) Characterization of CarboxylatedSWCNT Based Potentiometric DNA Sensors by Electrochemical Technique and Comparison with Potentiometric Performance. J Biosens Bioelectron 5: 157. doi: 10.4172/2155-6210.1000157

Copyright: @ 2014 Mamun MA, et al. This is an open-access article distributed under the terms of the Creative Commons Attribution License, which permits unrestricted use, distribution, and reproduction in any medium, provided the original author and source are credited. 
Citation: Mamun MA, Saleh Ahammad AJ (2014) Characterization of Carboxylated-SWCNT Based Potentiometric DNA Sensors by Electrochemical Technique and Comparison with Potentiometric Performance. J Biosens Bioelectron 5: 157. doi: 10.4172/2155-6210.1000157

given to characterization of surface charge density thus ensuring the quality of SWCNT based aptasensors. Furthermore, information, regarding different functionalized surfaces, is a potential need to ensure the modified surfaces. Consequently, except electrochemical techniques (e.g. CV) others aforementioned techniques do not ascertain clearly about the modification in various stages of functionalization. In the present study, characterization of thrombin aptasensors surfaces has been demonstrated based on $\mathrm{CV}$ response of $\left[\mathrm{Ru}\left(\mathrm{NH}_{3}\right)_{6}\right]^{3+}$ redox species interaction on different electrode surfaces. From the intensity of redox peaks the surface coverage on different modified electrodes were calculated and the amount of apatemers present on aptamer electrode surfaces were quantified. The detection of thrombin was achieved by potentiometry and allows correlation with $\mathrm{CV}$ results. These investigations promise reliable functionalization of surface through suitable characterization of electrode towards platforms for simple, accurate, precise and convenient detection of biomolecules.

\section{Experimental}

\section{Chemicals and Reagents}

All chemicals used were of analytical reagent grade. SWCNT were purchased from HeJi (Chaina) in bulk form with $>90 \%$ purity, $150 \mathrm{~mm}$ average length and $1.4-1.5 \mathrm{~nm}$ diameter. 15 -mer (5'-GGT TGG TGT GGT TGG-3') 5'-( $\left.\mathrm{CH}_{2}\right)_{6}-\mathrm{NH}_{2}$ anti-thrombin aptamers (TBA) were purchased from Eurogentec (London, UK). 1-ethyl3-(3-dimethylaminopropyl) carbodiimide hydrochloride (EDC), N-hydroxysuccinimide (NHS), 2-(N-morpholino)ethanesulfonic acid (MES), cetyl trimethylammonium bromide (CTAB), DMF (dimethyl formamide), $\left[\mathrm{Ru}\left(\mathrm{NH}_{3}\right)_{6}\right] \mathrm{Cl}_{3}(98 \%), \mathrm{NaCl}, \mathrm{KCl}, \mathrm{NaH}_{2} \mathrm{PO}_{4}$, $\mathrm{Na}_{2} \mathrm{HPO}_{4}$ and Tris-(hydroxymethyl) aminomethane were purchased from Sigma-Aldrich (Spain). All the chemicals (except SWCNTs) were used without purifications and the solutions were prepared with Milli-Q water $(>18.2 \mathrm{M} \Omega . \mathrm{cm})$ from a Millipore Inc. ultra-pure water system (Madrid, Spain). SWCNTs oxidation and purification were carried out following previously reported procedure [12]. For covalent functionalization of cSWCNT surfaces (Figure 1) on glassy carbon $(g c)$ electrode $\left(0.06 \mathrm{~cm}^{2}\right)$ we follow a very well known synthetic route [7b] which includes three major steps: i) carboxylated
SWCNT electrode, abbreviated as cSWCNT/gc, ii) activated cSWCNT/ $g c$ surface, labelled as SWCNT-COOR/gc and iii) covalently immobilized SWCNT based aptasensor, abbreviated as SWCNT-CO-NH-Aptamer/gc, illustrated in the following Figure 1.

cSWCNT/gc electrode: $g c$ substrate was cleaned, polished and sonicated before cSWCNT deposition. Carboxylated and pre- treated SWCNTs in DMF suspension $(1 \mathrm{mg} / \mathrm{mL}$ ) was deposited (about $30 \mu \mathrm{m}$ thick layer) by spraying (35 times) while being dried [13].

SWCNT-COOR/gc electrode: cSWCNT/gc electrode was dipped into freshly prepared $50 \mathrm{mM}$ NHS and $200 \mathrm{mM}$ EDC mixture (prepared in $50 \mathrm{mM}$ MES buffer pH 5.0) for $30 \mathrm{~min}$. and rinsed with PBS buffer.

SWCNT-CO-NH-Aptamer/gc electrode: This step used a wellknown carbodiimide-mediated wet-chemistry approach to form amide bonds between the amine spacer and the carboxylic moieties on the side walls of the nanotubes [14]. It was done by immersing SWCNTCOOR/gc electrode into $1 \mu \mathrm{M}$ aptamer solution overnight.

\section{Instrumental Setup and Measurements}

Measurement of CV using 3 electrodes (working electrode (WE), $\mathrm{Ag} / \mathrm{AgCl}$ reference electrode and glassy carbon rod counter electrode) in a single cell electrochemistry system containing $5 \mathrm{~mL} 10 \mathrm{mM}$ trisbuffer ( $\mathrm{pH} 7.4$ ) as electrolyte medium. $\mathrm{N}_{2}$ purging time $=15$ min with constant stirring before measurement. $\mathrm{N}_{2}$ blanket was maintained over the solution surface during scanning. Unless not specified, CVs were performed in the following conditions: potential window $500 \mathrm{mV}$ and - $1000 \mathrm{mV}$ at $100 \mathrm{mV} \mathrm{s}^{-1}$ scan rate. All the CVs were taken at ambient conditions.

Potentiometric detection of thrombin were carried out with a voltammeter using regenerated aptamer working electrode and $\mathrm{Ag} /$ $\mathrm{AgCl}$ double junction reference electrode in PBS buffer $(1 \mathrm{mM}, \mathrm{pH}$ 7.4). The solution was stirred while measuring at $1000 \mathrm{rpm}$.

Electrode regeneration: removal of $\mathrm{Ru}^{3+}$ from the electrode surface was done by dipping it at room temperature into $2 \mathrm{M} \mathrm{NaCl}$ solution for 1 hour after $\mathrm{CV}$ analysis as well as removal of thrombin using also $\mathrm{NaCl}$ $2 \mathrm{M}$ for $10 \mathrm{~min}$ after potentiometric measurements.

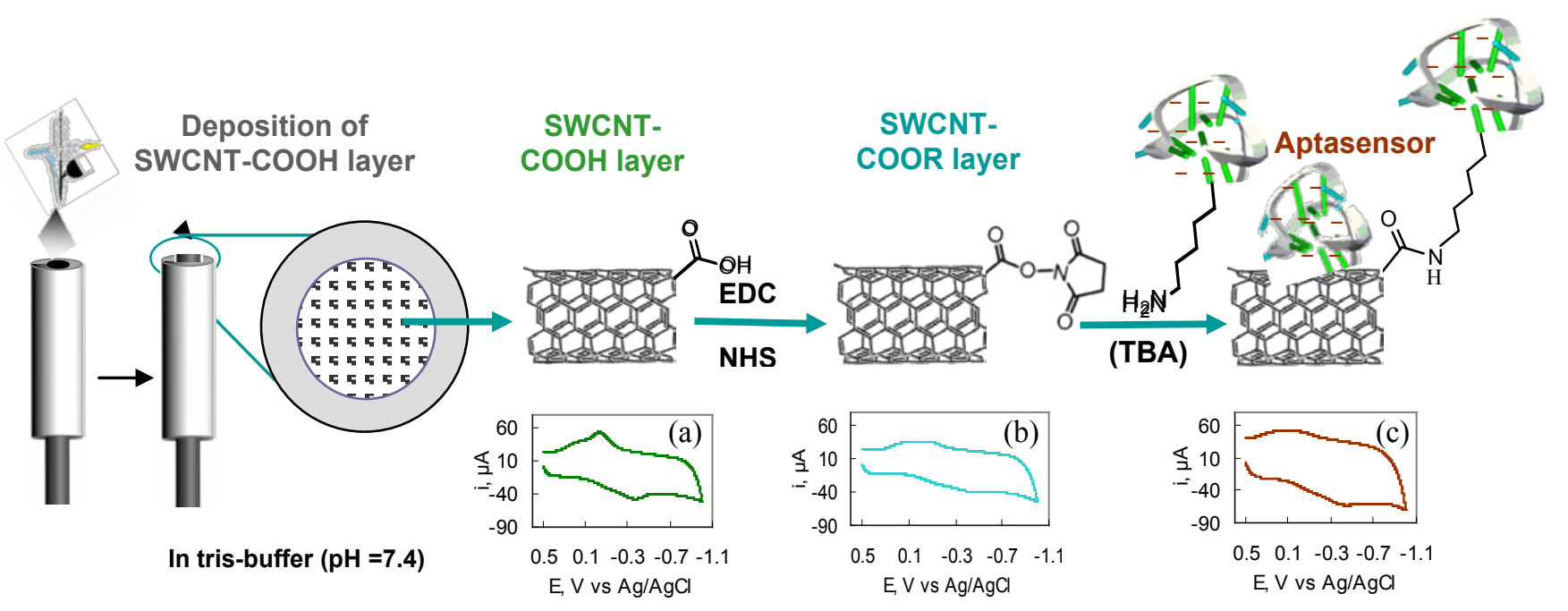

Figure 1: Different steps of construction of c-SWCNT based aptasensors and corresponding CVs of different modified surfaces at the scan rate $100 \mathrm{mVs} \mathrm{s}^{-1}$ between the potential window 500 and $-1000 \mathrm{mV}$ vs $\mathrm{Ag} / \mathrm{AgCl}$ at room temperature. 


\section{Results and Discussion}

From the CV experiments we have demonstrated the redox behaviour of $\left[\mathrm{Ru}\left(\mathrm{NH}_{3}\right)_{6}\right]^{3+}$ redox markers on different electrode surfaces and calculated double layer capacitance $\left(C_{D}\right)$, redox capacitance $\left(C_{R}\right)$, electrode surface area $(A)$ and $\mathrm{Ru}^{3+}$ surface coverage $\left(\Gamma_{\mathrm{Ru}}\right)$. The deduced $\Gamma_{\mathrm{Ru}}$ was used to estimate the aptamer surface charge density $\left(\Gamma_{\mathrm{A}}\right)$ in presence and absence of non-specifically adsorbed aptamers on SWCNT-CO-NH-Aptamer/gc electrode surface.

$\mathrm{C}_{\mathrm{D}}=\mathrm{dq} / \mathrm{dE}=\mathrm{idt} / \mathrm{dE}=\mathrm{i} /(\mathrm{dE} / \mathrm{dt})$ (calculated from the slope of the curve of $i$ vs scan rate) [15].

The redox capacitance has been calculated from the cathodic peak current in the Faradaic region at the scan rate $100 \mathrm{mVs}^{-1}$ using the equation [16]:

$$
\mathrm{C}_{\mathrm{R}}=\mathrm{i}_{\mathrm{pc}} /(\mathrm{dE} / \mathrm{dt})=\mathrm{i} / v
$$

where $i_{p c}$ is the current corresponding to the cathodic peak in the voltammogram and $v$ is the voltage scan rate in $\mathrm{mV} \mathrm{s}^{-1}$. The capacitance thus obtained is then compared to the reference value for cSWCNT $\left(\mathrm{C}^{*}=10 \mu \mathrm{F} / \mathrm{cm}^{2}\right)$ [17] so that the surface area is calculated from these equations:

$$
A_{D}=C_{D} / C^{*} \text { and ii) } A_{R}=C_{R} / C^{*} \text {. }
$$

Ruthenium surface coverage, $\Gamma_{\mathrm{Ru}}$ and aptamer surface charge density, $\Gamma_{\mathrm{A}}$ were calculated as prescribed in previous literature [11].

\section{Electrochemistry of different electrode surfaces:}

The CVs of different steps of functionalization in presence and in absence of redox markers were performed in different experimental conditions. We thus compared the electrochemical behavior of modified electrode surfaces.

Cyclic voltammograms (CVs) of catholytes (10 mM tris-buffer, $\mathrm{pH}$ 7.4): The CVs (Figure 2) of catholytes were taken in absence of redox species at room temperature in $5 \mathrm{ml}$ of $10 \mathrm{mM}$ trs-buffer ( $\mathrm{pH}$ 7.4) to observe the electrochemical behaviors of different electrode surfaces. In absence of redox species (Figure 2), a significantly large amount of background current or capacitative current were found on all the modified electrode surfaces compared to bare $g c$ surface. This probably indicates the high surface area and charge density of the electrode

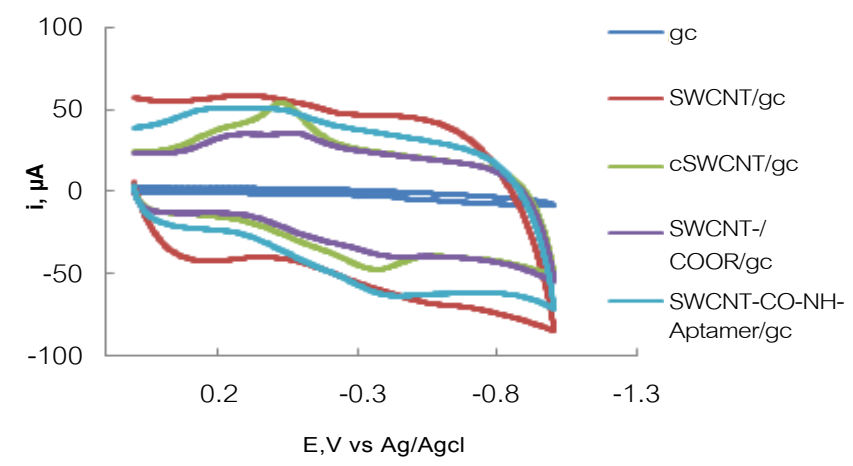

Figure 2: $\mathrm{CVs}$ of $10 \mathrm{mM}$ tris-buffer $(\mathrm{pH} 7.4)$ on different working electrodes at the scan rate $100 \mathrm{mVs}^{-1}$ between the potential window 500 and $-1000 \mathrm{mV}$ vs $\mathrm{Ag} / \mathrm{AgCl}$ at room temperature.

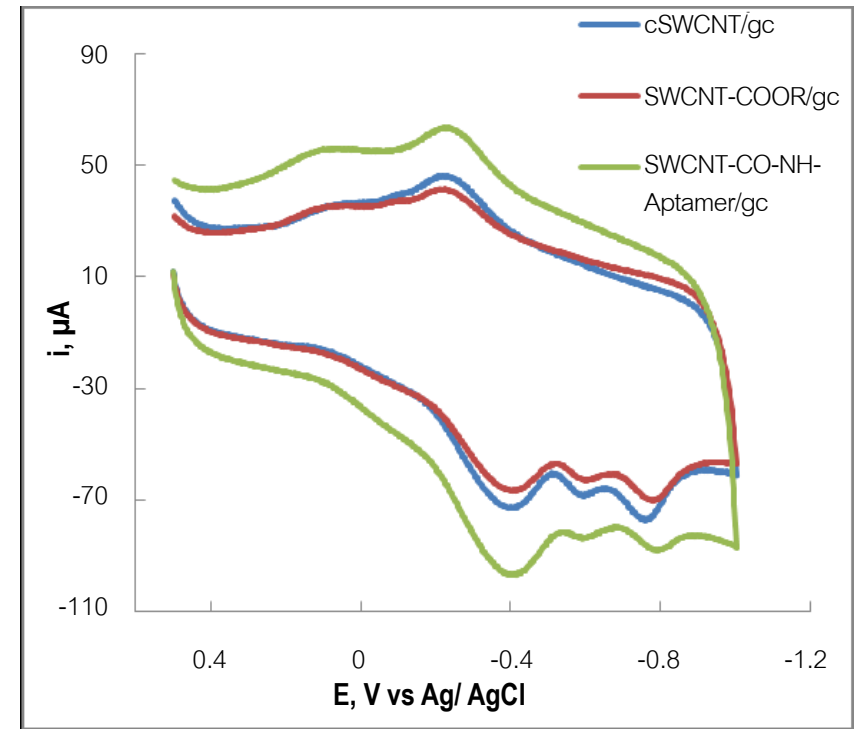

Figure 3: Redox behavior of $[\mathrm{Ru}(\mathrm{NH} 3) 6]^{3+}$ on different working electrode surfaces at the scan rate $100 \mathrm{mV} \mathrm{s}^{-1}$ between the potential window 500 and $-1000 \mathrm{mV}$ vs $\mathrm{Ag} / \mathrm{AgCl}$ at room temperature.

surfaces due to the incorporation of SWCNTs as a transduction layer [18b]. Figure 2 shows one pair of redox peaks at $\mathrm{E}_{\mathrm{pa}}=-17.5 \mathrm{mV}$ and $\mathrm{E}_{\mathrm{pc}}=-378 \mathrm{mV}$ corresponding to the cSWCNT/gc surface. These redox peaks (Figure 2: pink line) demonstrates the presence of $-\mathrm{COOH}$ groups as previously reported by Hongxia et al. [19] After activation and subsequent aptamer immobilization it was noted that these redox peaks indeed disappeared.

Redox behavior of $\left[\mathrm{Ru}\left(\mathrm{NH}_{3}\right)_{6}\right]^{3+}$ on different electrode surfaces (Figure3) were studied at different concentrations of redox species up to saturation of the surfaces. These experiments were conducted to observe the redox behaviours of $\left[\mathrm{Ru}\left(\mathrm{NH}_{3}\right)_{6}\right]^{3+}$ and find out at which range of concentrations the different electrode surfaces are being saturated by $\left[\mathrm{Ru}\left(\mathrm{NH}_{3}\right)_{6}\right]^{3+}$ ions.

In presence of $\left[\mathrm{Ru}\left(\mathrm{NH}_{3}\right)_{6}\right]^{3+}$ the CVs show one anodic peak $\left(\mathrm{E}_{\mathrm{pa}}=\right.$ $-213,-208$ and $-220 \mathrm{mV}$ for cSWCNT, SWCNT-COOR and aptamer surfaces respectively) and three cathodic peaks. $1^{\text {st }}$ cathodic peak, $\mathrm{E}_{\mathrm{pc}} 1$ on cSWCNT, SWCNT-COOR and for aptamer surfaces was found at $-413,-412$ and $-418 \mathrm{mV}, 2^{\text {nd }}$ and $3^{\text {rd }}$ cathodic peaks were found at $\mathrm{E}_{\mathrm{pc}} 2$ $=-606,-608$ and $-609 \mathrm{mV}$ and $\mathrm{E}_{\mathrm{pc}} 3=-774,-789$ and $-806 \mathrm{mV}$ respectively. Noteworthy, among them $2^{\text {nd }}$ and 3 rd cathodic peaks show completely irreversible behavior. Higher peak separation potential $(\sim 200 \mathrm{mV})$ implies slow electron transfer process. The peak current ratio $\left(i_{\mathrm{pc}} 1 / i_{\mathrm{pa}}\right)$ for cSWCNT/gc and SWCNT-COOR/gc electrode surface complies with the reversible redox process whereas the aptamer-cSWCNT/gc surface exhibits quasi-reversible charge transfer process. The $2^{\text {nd }}$ and $3^{\text {rd }}$ cathodic peaks disappeared during the $2^{\text {nd }}$ scan accounting for no further oxidation or reduction of that particular species. That would imply the presence of impurity in $\mathrm{Ru}$-complex which forms trimer (coloured) in solution [18a]. Since the trimer has both +3 and +4 oxidation states of ruthenium we can proposed the following redox mechanism for the corresponding peaks observed in the $\mathrm{CV}$ as reported in literature $[9,11,18 \mathrm{a}]$. 
$1^{\text {st }}$ cathodic peak: $\mathrm{Ru}^{3+}+\mathrm{e}^{-} \rightarrow \mathrm{Ru}^{2+}$

$2^{\text {nd }} \& 3^{\text {rd }}$ cathodic peak: $\mathrm{Ru}^{4+}+\mathrm{e}^{-} \rightarrow \mathrm{Ru}^{3+}+\mathrm{e}^{-} \rightarrow \mathrm{Ru}^{2+}$

Anodic peak: $\mathrm{Ru}^{2+}-\mathrm{e}^{-} \rightarrow \mathrm{Ru}^{3+}$

The nature of the surface saturation curves were studied on different electrode surfaces taking CVs for a series of $\left[\mathrm{Ru}^{3+}\right](1 \mu \mathrm{M}$ to $120 \mu \mathrm{M})$. It was noted that saturation attains at about $3 \mu \mathrm{M}$ to $5 \mu \mathrm{M}$ on cSWCNT/gc, $\sim 3 \mu \mathrm{M}$ on SWCNT-COOR/gc and $\sim 50 \mu \mathrm{M}$ on Aptamer$\mathrm{NH}-\mathrm{CO}-\mathrm{SWCNT} / g c$ surfaces. The saturation point for aptamer electrode surfaces were not clearly defined as other two electrode surfaces. The presence of different functional moieties along with phosphate groups in aptamer molecules might be responsible for this difference. The concentration profiles follow the Langmuir adsorption isotherms which agree with others reports for aptamer surface and oxygen rich electrode surface $[9,11]$. However, as the binding constant of $\left[\mathrm{Ru}\left(\mathrm{NH}_{3}\right)_{6}\right]^{3+}$ to DNA is larger than that of $\left.\mathrm{Ru}\left(\mathrm{NH}_{3}\right)_{6}\right]^{2+}$ to DNA, the cathodic peak current was higher than that of anodic peak [11].

The surface behavior of different electrodes were also observed at various scan rates (10 to $400 \mathrm{mV} \mathrm{s}$ ) between the potential window 0 to $-700 \mathrm{mV}$ as shown in Figure 4a for Aptamer-NH-CO-SWCNT surfaces. From the $\mathrm{CV}$ studies on all the three different electrode surfaces it was found that with the increase of scan rate the peak current increases linearly which complies with the adsorption control electron transfer process through the electrode-solution interfaces which is in good agreement with previous reports for aptamer surfaces $[9,11]$. Since the SWCNT surfaces are porous, and carboxylated and esterified, SWCNT surfaces are also oxygen rich surface, adsorption of $\mathrm{Ru}^{3+}$ on the surface will dominate the electron transfer process over diffusion process. For example, the Randless-Sevcic plot (Figure $4 \mathrm{~b}$ : intensity $v s$ square root of the scan rate) for the corresponding CVs of Figure $4 \mathrm{a}$ indicates that the electrode process is not purely diffusion controlled because it does not follow linearity at the lower scan rates $(<100 \mathrm{mV}$ $\left.\mathrm{s}^{-1}\right)$. Therefore, the rate of electron transfer depends not only on the concentration and diffusional properties of the electroactive species but also on scan rate for this electrochemical process [20]. Figure 4a also demonstrates that the $\mathrm{E}_{\mathrm{pc}}$ shifted towards right (more negative potential) and the $\mathrm{E}_{\mathrm{pa}}$ shifted towards left (more positive potential) and hence peak separation $\left(\Delta \mathrm{E}_{\mathrm{p}}\right)$ also increases with the increase of scan rate. This redox behavior also supports the slow charge transfer kinetics.

\section{Estimation of Surface Charge Density}

The exact surface area of a porous electrode plays an important role for correct estimation of surface charge density. However, surface area is one of the parameters which characterize a porous electrode, and the double layer capacitance is known to provide a reliable estimation of the surface area effective for participation in electrochemical reactions [21]. In order to compare our results we have calculated the electrode surface area using both types of electrochemical capacitance such as double-layer capacitance $\left(C_{D}\right)$ and redox capacitance $\left(C_{R}\right)$. On the basis of some theoretical considerations like (i) ideal polarizability over limited potential ranges in the non-faradaic regions [21], ii) for an ideal double .

\section{Steps involve for the calculation Surface Charge Density}

Layer capacitor the shape of CV looks like a rectangle (Figure 5a) within this limited potential window [22] and (iii) the state of charge of a surface is strongly dependent on the solution $\mathrm{pH}$ [15], cyclic voltammetric curves were recorded (Figure5a) in a narrow potential range (within the non-faradaic region: $-550 \mathrm{mV}$ to $-650 \mathrm{mV}$ ) in absence of redox species in $10 \mathrm{mM}$ tris buffer $(\mathrm{pH} 7.4)$ at different scan rates (5, $10,15,20,25$ and $\left.30 \mathrm{mV} \mathrm{s}^{-1}\right)$. The current in the middle $(\sim 601.196 \mathrm{mV})$ of the potential window is then plotted as a function of the scan rate. Under the assumption that double layer charging is the only process, the slope of the straight line obtained from the plot (Figure $5 \mathrm{~b}$ ) gives the differential capacitance (total value) of the interface.

From the calculated data (Table 1) it is observed that $C_{R}$ for esterified and aptamer modified surfaces are higher than the $C_{D}$ values in the non-faradaic region. The explanation of this discrepancy may be sought in terms of adsorption pseoudocapacitance [21] (which may arise from the diffusion within the porous electrode surface and when adsorbed species participates in the rate-determining steps of overall charge transfer process), which was neglected in the present experiment. By studying CVs on different electrode surfaces it is found that the $C_{D}$ value and corresponding surface area (Table
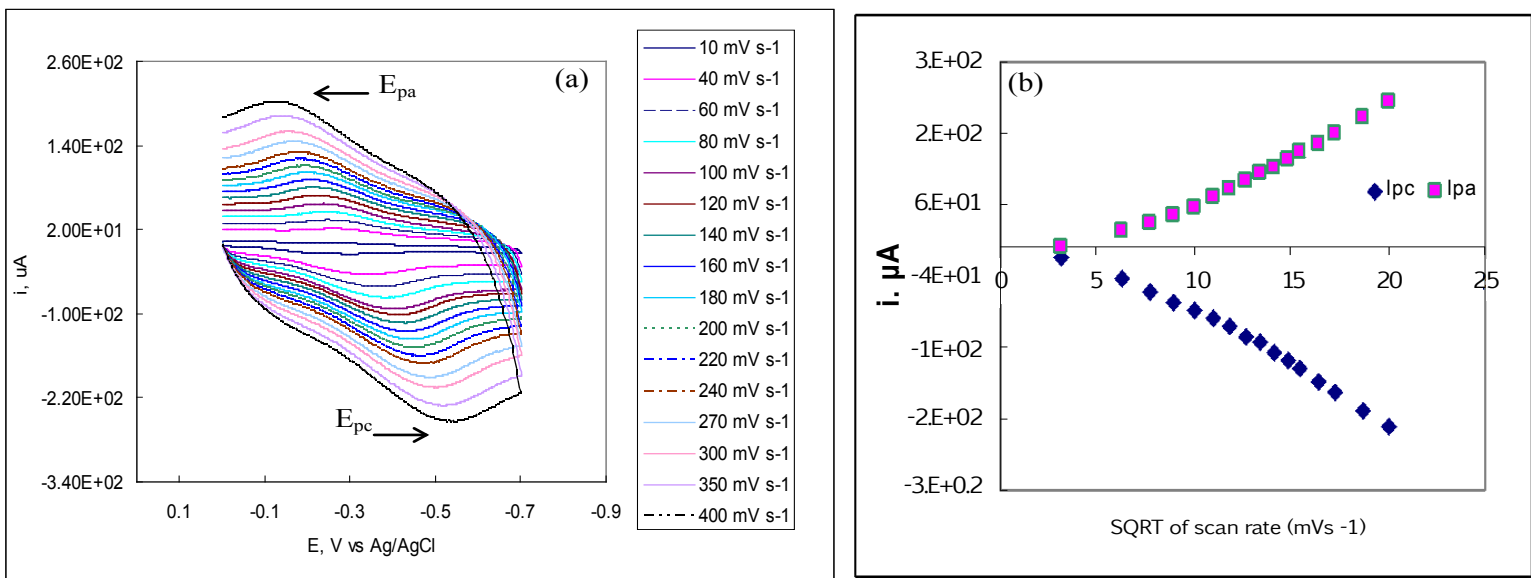

Figure 4: (a) Redox behavior of $\mathrm{Ru}^{3+}$ on Aptamer-NH-CO-SWCNT/gc electrode at different scan rates between the potential window $0 \mathrm{mV}$ to $-700 \mathrm{mV}$ in tris-buffer ( $\mathrm{pH}$ 7.4). (b) Corresponding Randles-Sevcic plot for (a): variation of anodic and cathodic peak current at different SQRT of scan rates (mVs $\left.{ }^{-1}\right)$. 

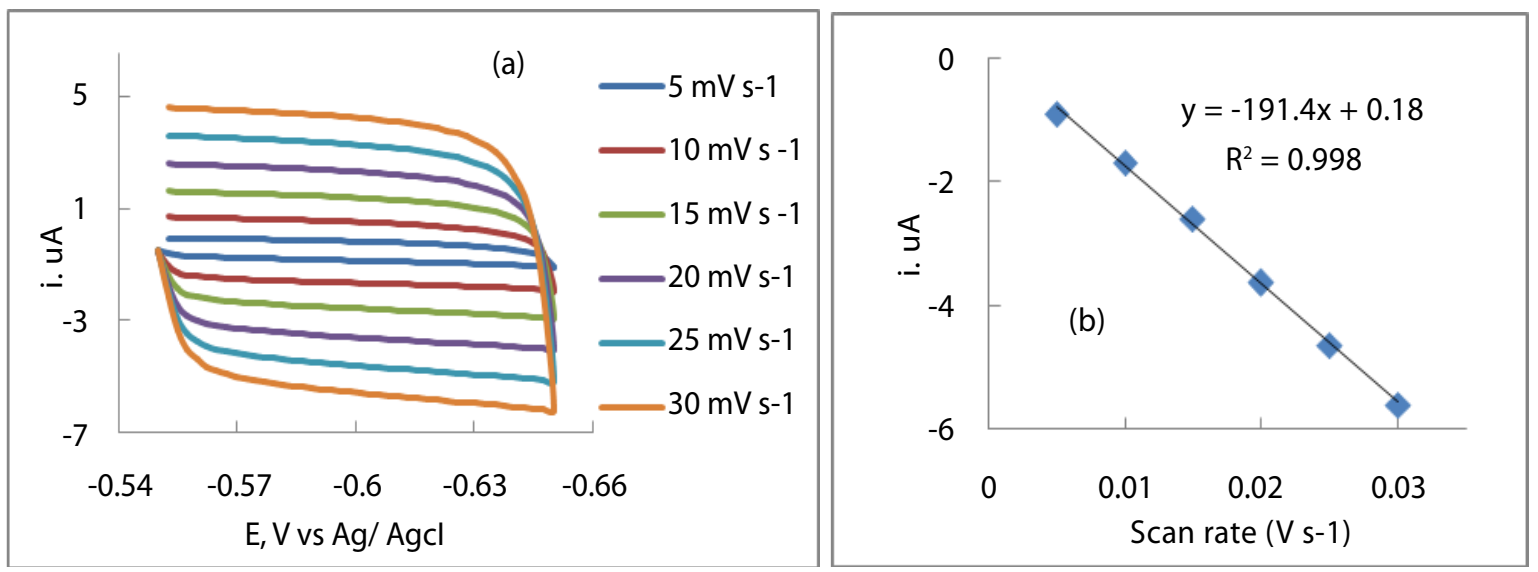

Figure 5: (a) $\mathrm{CVs}$ of catholytes (tris-buffer, $\mathrm{pH}=7.4$ ) at various scan rates between the potential range, $-550 \mathrm{mV}$ to $-650 \mathrm{mV}$ at room temperature. (b) Calculation of double layer capacitance from the slope of plot of $i(\mu \mathrm{A})$ vs scan rates $\left(\mathrm{Vs}^{-1}\right)$.

\begin{tabular}{|c|c|c|c|c|c|c|}
\hline & \multicolumn{2}{|c|}{ Capacitance, $\mathrm{C}(\mu \mathrm{F})$} & \multicolumn{2}{|c|}{ Electrode surface area, $A\left(\mathrm{~cm}^{2}\right)$} & \multicolumn{2}{|c|}{$\mathrm{Ru}^{3+}$ surface coverage, $\Gamma_{\mathrm{Ru}}\left(\right.$ mole $\left.\mathrm{cm}^{-2}\right) \times \mathrm{e}^{11}$} \\
\hline & $C_{D}$ & $C_{R}$ & $A_{D}$ & $A_{R}$ & $\Gamma_{\mathrm{Ru}, \mathrm{D}}$ & $\Gamma_{\mathrm{Ru}, \mathrm{R}}$ \\
\hline A & $41.0 \pm 3510$ & - & $41.0 \pm 35$ & - & - & - \\
\hline B & $309 \pm 28$ & $256 \pm 7$ & $30.9 \pm 2.8$ & $25.6 \pm 0.7$ & $2.52 \pm 0.04$ & $3.04 \pm 0.01$ \\
\hline C & $211 \pm 21$ & $221 \pm 20$ & $21.1 \pm 2.1$ & $22.1 \pm 2.0$ & $2.54 \pm 0.03$ & $2.43 \pm 0.02$ \\
\hline $\mathrm{D}$ & $268 \pm 30$ & $278 \pm 36$ & $26.8 \pm 2.9$ & $27.8 \pm 3.6$ & $2.65 \pm 0.10$ & $2.56 \pm 0.08$ \\
\hline
\end{tabular}

Table 1: Calculated data $\left(C_{D}, C_{R}, A_{D}, A_{R}\right.$ and $\left.\Gamma_{R u}\right)$ for different electrodes $(A=S W C N T / g c, B=c S W C N T / g c, C=S W C N T-C O O R / g c, D=A p t a m e r-N H-C O-S W C N T / g c)$.

1) are decreased in the order: SWCNT/gc>cSWCNT/gc>Aptamer$\mathrm{NH}-\mathrm{CO}-\mathrm{SWCNT} / g c>\mathrm{SWCNT}-\mathrm{COOR} / g c$. These results indicate that modification of SWCNT surface influence on $C_{D}$ and surface area of electrodes due to the variation of surface charge density. In case of redox capacitance for SWCNT/gc surface were not reported (Table 1) due to very low response to redox species. Among all the modified SWCNT surfaces, maximum $\mathrm{Ru}^{3+}$ surface coverage was found on aptamer functionalized surface $\left(2.65 \pm 0.10 \mathrm{mols} / \mathrm{cm}^{2}\right)$ considering $A_{D}$ but considering $C_{R}$ it was maximum on $c S W C N T / g c$ electrode due to lower redox surface area (Table 1). These results provide strong evidence for the electrochemistry of CNT modified electrode surface which are dominated by the behavior of functional groups present at the ends of the carbon nanotubes.

After $\mathrm{CV}$ analysis the adsorbed $\mathrm{Ru}^{3+}$ ions were removed (Figure 6) by dipping the electrodes in $2 \mathrm{M} \mathrm{NaCl}$ solution for 1 hour and the regeneration of surfaces were confirmed by comparing the CVs in trisbuffer after and before regeneration of the electrode surfaces. Then the same aptasensors (aptamer-NH-CO-SWCNT/gc) were used for potentiometric detection of thrombin in order to confirm the presence of aptamers on the electrode surfaces.

\section{Potentiometric detection of Thrombin}

Figure 7 illustrates the potentimetric response of thrombin in $5 \mathrm{~mL}$ of $1 \mathrm{mM}$ PBS buffer (pH 7.4) at different concentrations of thrombin analytes for regenerated aptasensors. Following addition of analyte, the signal increases rapidly and reaches the plateaus indicate the presence of aptamer on the electrode surface. After potentiometric measurements the electrodes were regenerated in $2 \mathrm{M} \mathrm{NaCl}$ solution for $10 \mathrm{~min}$. From potentiometric measurements for five aptasensors (Figure 8a) it was found that all the electrodes were giving significant response.

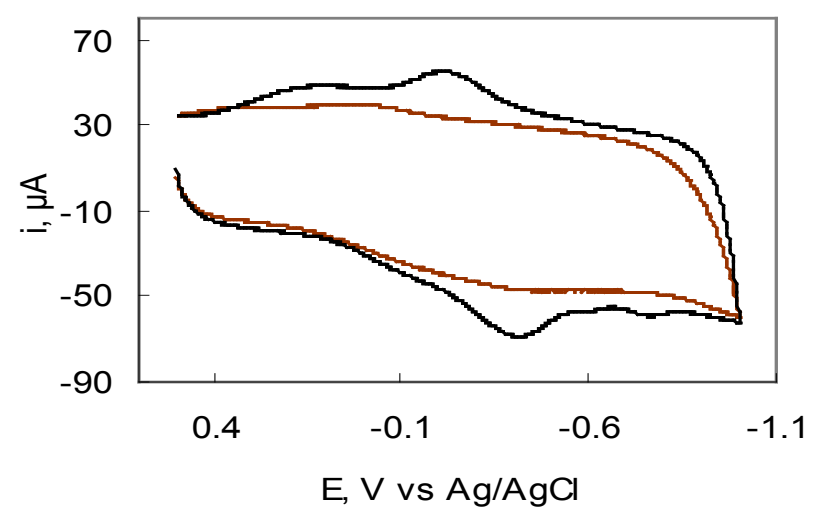

Figure 6: Confirmation of removal of $\mathrm{Ru}^{3+}$ from electrode surface: (a) red line indicates the $\mathrm{CV}$ after removal of $\mathrm{Ru}^{3+}$ in $2 \mathrm{M} \mathrm{NaCl}$ solution and (b) black line indicates the $\mathrm{CV}$ in presence of $\mathrm{Ru}^{3+}$.

The highest potentiometric signals were found for working electrode (WE)-3 and -5. There is also a good agreement in corresponding CV results illustrated in Figure 8b. The electrodes that give higher peak current in $\mathrm{CV}$ analysis also show higher sensitivity to thrombin analyte in potentiometric measurements. However, these two electrodes contain higher number of aptamers (WE-3: $96.60 \times 10^{12}$ molecules and WE-5 : $97.83 \times 10^{12}$ molecules on their surfaces due to higher redox surface area, $A_{R}$ (WE-3: $30 \mathrm{~cm}^{2}$ and WE-5: $32.5 \mathrm{~cm}^{2}$ ) compare to others electrodes (Table 2). It is very interesting to note that the calculated results using double layer capacitance also corresponds to this order.

\section{Reproducibility}

Figure 8 depicts the reproducibility of aptasensor regarding the 
Citation: Mamun MA, Saleh Ahammad AJ (2014) Characterization of Carboxylated-SWCNT Based Potentiometric DNA Sensors by Electrochemical Technique and Comparison with Potentiometric Performance. J Biosens Bioelectron 5: 157. doi: 10.4172/2155-6210.1000157

Page 6 of 8

data obtained from $\mathrm{CV}$ and potentiomentry for three consecutive measurements on the same aptsensor. It is noted that (Figure $9 \mathrm{a}$ and b) the aptasensor (SWCNT-CO-NH-Aptamer/gc electrode) is fairly reproducible.

Because the non-specifically adsorbed aptamers may interfere the reproducibility of aptasensor due to unstable electrode surface. However, when two consecutive CV experiments were conducted at higher scan rate using the same apatasensor, the saturation peak current was decreased significantly in the $2^{\text {nd }}$ experiments. It accounts for the removal of non-covalently attached aptamers at higher scanning potential during the $1^{\text {st }} \mathrm{CV}$ measurements. Limit of detection (LOD) and sensitivity of the aptasensors were also calculated by using potentiometric calibration curves. The sensitivity and LOD for five aptasensors were found as $3.853 \pm 1.491$

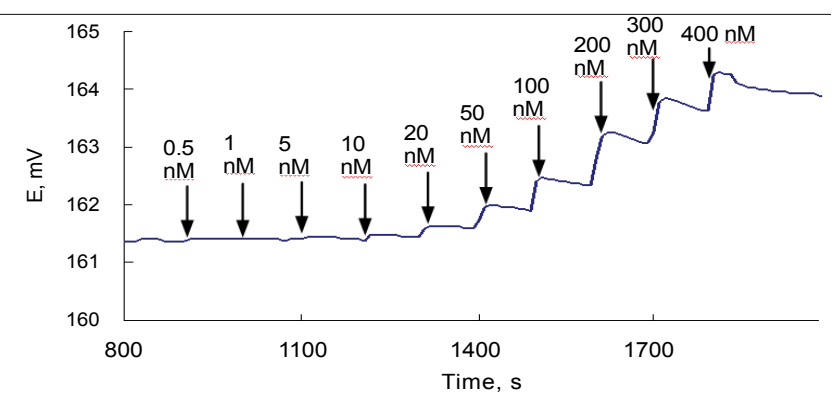

Figure 7: Potentiometric response of thrombin in $5 \mathrm{ml}$ of $1 \mathrm{mM}$ PBS buffer $(\mathrm{pH}=7.4)$ solution at ambient temperature.
$\mathrm{mV} / \log \mathrm{a}_{\mathrm{Thr}}$ and $6.88 \pm 3.55 \mathrm{e}^{-8} \mathrm{M}$ respectively.

\section{Aptamer surface charge density}

The calculated aptamer surface charge densities (Table 2) for five electrodes were found as $3.19 \pm 0.12 \mathrm{e}^{12}$ molecules $\mathrm{cm}^{-2}$ with respect to (w.r.t.) $C_{D}$ whereas $3.08 \pm 0.09 \mathrm{e}^{12}$ molecules $\mathrm{cm}^{-2}$ was found w.r.t. $\mathrm{C}_{\mathrm{R}}$ which are quite comparable to each other.

\section{Conclusions}

By analysis all the CV and potentiometric data as demonstrated herein, we can conclude that cyclic voltammetric technique can be used as easy and less expensive technique to successfully build potentiommetric aptasensors via characterizing the surface by determining the aptamer surface charge density. Since the CV saturation curves (Figure 9b) demonstrate that the ruthenium concentration for saturation is comparable, the calculated aptamer surface charge density is very reliable and significant if we consider the reference value of capacitance for cSWCNT, $C^{*}=10 \mu \mathrm{F} / \mathrm{cm}^{2}$ is the same for all the electrode surfaces either after covalent immobilization or non-covalent immobilization of aptamers. But practically it is not same for all the surfaces. So if we want to determine the exact amount of aptamers on the electrode surfaces we need the reference value for covalently functionalized aptamer-SWCNT. However, it is also essential to remove the non-specifically or non-covalently adsorbed aptamer from the electrode surface in case of co-valent functionalization, since it is directly related with the reproducibility of the aptasensors. Nevertheless, the method is useful for an internal comparison and to judge the
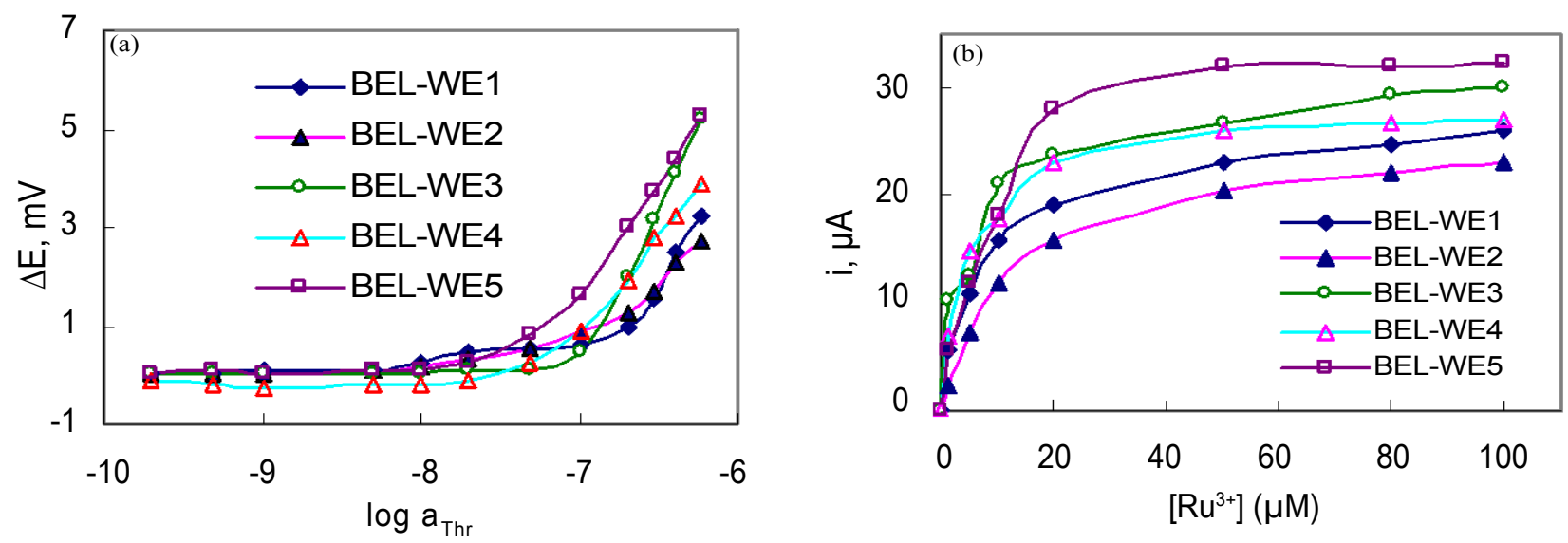

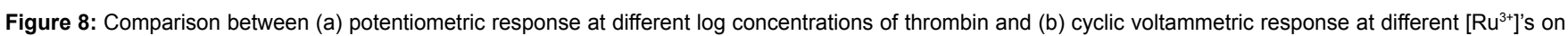
different five aptasensors (Aptamer-NH-CO-SWCNT/gc).

\begin{tabular}{|c|c|c|c|c|c|c|c|c|}
\hline \multirow{2}{*}{ WE } & \multicolumn{2}{|c|}{ Capacitance, C ( $\mu \mathrm{F})$} & \multicolumn{2}{|c|}{ Electrode surface area, $\mathbf{A}\left(\mathrm{cm}^{2}\right)$} & \multicolumn{2}{|c|}{$\mathrm{Ru}^{3+}$ surface coverage, $\Gamma_{\mathrm{Ru}}\left(\right.$ mole $\left.\mathrm{cm}^{-2}\right) \times \mathrm{e}^{11}$} & \multicolumn{2}{|c|}{ Aptamer surface, charge density, $\Gamma_{A}\left(\right.$ molecules $\left.\mathrm{cm}^{-2}\right) \times \mathrm{e}^{-12}$} \\
\hline & $C_{D}$ & $\mathrm{C}_{\mathrm{R}}$ & $A_{D}$ & $A_{R}$ & $\Gamma_{\mathrm{Ru}, \mathrm{D}}$ & $\Gamma_{\mathrm{RU}, \mathrm{R}}$ & $\Gamma_{\mathrm{A}, \mathrm{D}}$ & $\Gamma_{A, R}$ \\
\hline 1 & 255 & 260 & 25.5 & 26.0 & 2.66 & 2.61 & 3.20 & 3.14 \\
\hline 2 & 229 & 231 & 22.9 & 23.1 & 2.54 & 2.52 & 3.06 & 3.04 \\
\hline 3 & 285 & 300 & 28.5 & 30.0 & 2.81 & 2.67 & 3.38 & 3.22 \\
\hline 4 & 264 & 272 & 26.4 & 27.2 & 2.58 & 2.50 & 3.10 & 3.01 \\
\hline 5 & 307 & 325 & 30.7 & 32.5 & 2.65 & 2.50 & 3.19 & 3.01 \\
\hline$\overline{\mathrm{A}} \pm$ & 268 & 278 & 26.8 & 27.8 & 2.65 & 2.56 & 3.19 & 3.08 \\
\hline RSD & \pm & \pm & \pm & \pm & \pm & \pm & \pm & \pm \\
\hline & 30 & 36 & 2.9 & 3.6 & 0.10 & 0.08 & 0.12 & 0.09 \\
\hline
\end{tabular}

Table 2: Calculated data obtained from CV studies on five Aptamer-NH-CO-SWCNT/gc electrode surfaces. 

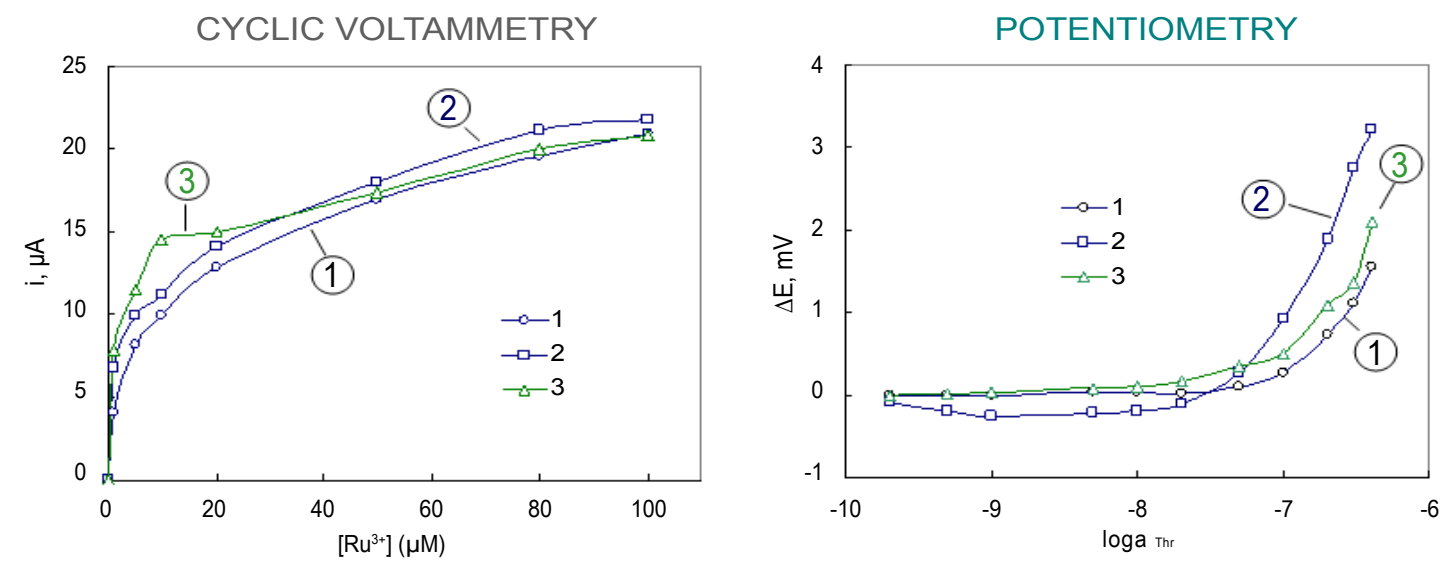

Figure 9: Reproducibility: (a) cyclic voltammetric response at different [Ru $\left.{ }^{3+}\right]^{\prime}$ and (b) Potentiometric response at different log concentrations of thrombin for three consecutive measurements on same aptasensor.

quality of electrode surfaces for appropriate experimental conditions Furthermore, we can infer that there is a good correlation between $\mathrm{CV}$ and potentiometric results. Because the electrode containing more covalently functionalized aptamers are showing better sensitivity during the detection of thrombin. Searching of noble technique to eliminate the non-specifically bound aptamers on the electrode surface maintaining the stability of the surfaces will be further investigated.

\section{Acknowledgment}

Authors are grateful to URV, Spain and Jagannath University, Dhaka for making facilities to practice science in a congenial and comfortable atmosphere.

\section{References}

1. Winzeler EA, Richards DR, Conway AR, Goldstein AL, Kalman S, et al. (1998) Direct allelic variation scanning of the yeast genome. See comment in PubMed Commons below Science 281: 1194-1197.

2. (a) Abbott A (1999) A post-genomic challenge: learning to read patterns of protein synthesis. Nature 402: 715-720; 2(b) Blobel G, Wozniak RW (2000) Structural Biology: Proteomics for the pore. Nature 403: 835-836; 2(c) Smirnov I and Shafer RH (2000) Effect of loop sequence and size on DNA aptamer stability. Biochemistry 39: 1462-1468.

3. (a) Xu D, Xu D, Yu X, Liu Z, He W, Ma Z (2005) Label-free electrochemical detection for aptamer-based array electrodes. Anal. Chem.77: 5107-5113; 3(b) Ikebukuro K, Kiyohara C, Sode K(2004) Aptamers as molecular recognition elements for electrical nanobiosensors. Anal. Lett. 27: 2901-2909; 3(c) Fernández E G, d-I-S-Álvarez N, L-Castañón MJ, M-Ordieres AJ, T-Blanco $P(2011)$ Impedimetric aptasensor for tobramycin detection in human serum. Biosensors and Bioelectronics 26: 2354-2360.

4. Wang J, Liu G, Jan MR (2004) Ultrasensitive electrical biosensing of proteins and DNA: carbon-nanotube derived amplification of the recognition and transduction events. See comment in PubMed Commons below J Am Chem Soc 126: 3010-3011.

5. Das J, Aziz MA, Yang $H$ (2006) A nanocatalyst-based assay for proteins: DNA-free ultrasensitive electrochemical detection using catalytic reduction of p-nitrophenol by gold-nanoparticle labels. See comment in PubMed Commons below J Am Chem Soc 128: 16022-16023.

6. Li W, Nie Z, Xu X, Shen Q, Deng C, et al. (2009) A sensitive, label free electrochemical aptasensor for ATP detection. See comment in PubMed Commons below Talanta 78: 954-958.

7. (a) Z-Guillén G, Boshale SV, Riu J, Rius FX (2010), Real-time potentiometric detection of bacteria in complex samples. Anal. Chem 82: 9254-9260; 7(b) Z-Guillen GA, Riu J, Duzgun A, and Rius FX (2009), Immediate detection of living bacteria at ultralow concentrations using a carbon nanotube based potentiometric aptasensor. Angew. Chem. Int. Ed., 48, 7334 -7337.
8. (a) Peterlinz KA, Georgiadis RM, Herne TM, Tarlov MJ (1997) Observation of hybridization and dehybridization of thiol-tethered DNA using two-color surface plasmon resonance spectroscopy. J. Am. Chem. Soc.119: 3401-3402; 8(b) Campbell CN and Heller A (1999) Electrochemical study of electron transport through thin DNA films. J. Am. Chem. Soc.121: 10803-10812; (c) Petrovykh DY, K-Suda H, Whitman LJ, Tarlov MJ (2003) Quantitative analysis and characterization of DNA immobilized on gold. J. Am. Chem. Soc. 125: 5219-5226.

9. Yu HZ, Luo CY, Sankar CG, Sen D (2003) Voltammetric procedure for examining DNA-modified surfaces: quantitation, cationic binding activity, and electron-transfer kinetics. See comment in PubMed Commons below Anal Chem 75: 3902-3907.

10. Lao R, Song S, Wu H, Wang L, Zhang Z, et al. (2005) Electrochemical interrogation of DNA monolayers on gold surfaces. See comment in PubMed Commons below Anal Chem 77: 6475-6480.

11. Ge B, Y-Chuan, Sen D, Yu HZ (2007) Electrochemical investigation of DNAmodified surfaces: from quantitation methods to experimental conditions. J. of Electroanal. Chem. 602: 156-162.

12. Furtado CA, Kim UJ, Gutierrez HR, Pan L, Dickey EC, et al. (2004) Debundling and dissolution of single-walled carbon nanotubes in amide solvents. See comment in PubMed Commons below J Am Chem Soc 126: 6095-6105.

13. Crespo GA, Macho S, Bobacka J, Rius FX (2009) Transduction mechanism of carbon nanotubes in solid-contact ion-selective electrodes. See comment in PubMed Commons below Anal Chem 81: 676-681.

14. Wong SS, Joselevich E, Woolley AT, Cheung CL, Lieber CM (1998) Covalently functionalized nanotubes as nanometre-sized probes in chemistry and biology. See comment in PubMed Commons below Nature 394: 52-55.

15. Trasatti S, Petrii OA (1991) Real surface area measurements in electrochemistry. Pure and Appl. Chem. 63:711-734.

16. Mini PA, Balakrishnan A, Nair SV, Subramanian KR (2011) Highly supe capacitive electrodes made of graphene/poly(pyrrole). See comment in PubMed Commons below Chem Commun (Camb) 47: 5753-5755.

17. Shiraishi S, Kurihara H, Okabe K, Hulicova D, Oya A (2002) Electric double layer capacitance of highly pure single-walled carbon nanotubes ( $\mathrm{HiPco}$ Buckytubes) in propylene carbonate electrolytes. Electrochem. Commun. 4 593-598.

18. (a) C-Villalón P, Ramírez P, Peltre MJ, Louis $C$ and Massiani $P$ (2009) An UV-Visible study of the stability of the ruthenium hexaammine cation in BEA zeolites comparison with NaY. Phys. Chem. Chem. Phys. 6: 3739-3746 18(b) Heras A, Colina A, L-Palacios J, Ayala P, Sainio J, Ruiz V, Kauppinen EI (2009) Electrochemical purification of carbon nanotube electrodes. Electrochem. Commun. 11: 1535-1538.

19. Luo H1, Shi Z, Li N, Gu Z, Zhuang Q (2001) Investigation of the electrochemical and electrocatalytic behavior of single-wall carbon nanotube film on a glassy 
Citation: Mamun MA, Saleh Ahammad AJ (2014) Characterization of Carboxylated-SWCNT Based Potentiometric DNA Sensors by Electrochemical Technique and Comparison with Potentiometric Performance. J Biosens Bioelectron 5: 157. doi: 10.4172/2155-6210.1000157

Page 8 of 8

carbon electrode. See comment in PubMed Commons below Anal Chem 73 : 915-920

20. Bard AJ, Faulkner LR (2001) Electrochemical Mehods, John Wiley and Sons, New York: 12-18.
21. Tilak BV, Rader CG, Rangarajan SK (1977) Techniques for characterizing porous electrodes I: Determination of the double layer capacity. J. Electrochem. Science and Tech.124: 1879-1886.

22. Conway BE (1999) Electrochemical supercapacitors: Scientific fundamentals and technological applications, Kluwer Academic/Plenum Publishers, New York. 